Dunamis: Jurnal Teologi dan Pendidikan Kristiani

Volume 4, Nomor 1 (Oktober 2019)

ISSN 2541-3937 (print), 2541-3945 (online)

http://www.sttintheos.ac.id/e-journal/index.php/dunamis

\title{
Orang Kristen dan Politik: Belajar dari Kasus Salomo dan Adonia dalam Persaingan Menuju Takhta
}

\author{
Yohanes Krismantyo Susanta \\ Program Studi Musik Gerejawi STAKN Toraja \\ yohanessusanta@gmail.com
}

\begin{abstract}
This article aimed to give theological biblical insight how Christian should be involved in politics. Trough narrative interpretation to the books of 1 Kings 1-2 revealed the rivalry between Solomon and Adonijah for the throne filled with intrigue and political exclusion. Trough this analysis shown that the story could not be used as theological justification but as an example so that the same incident does not happen anymore. On the other hand Christians also need to understand that politics is an effort in embodying love and justice for others.
\end{abstract}

Keywords: politics; Christians; Solomon; Adonijah; narrative interpretation; 1 Kings

\begin{abstract}
Abstrak
Artikel ini bertujuan untuk memberikan pemahaman teologis biblis bagaimana sikap umat Kristiani dalam menghadapi perpolitikan nasional. Melalui pendekatan tafsir naratif terhadap teks 1 Raja-raja 1-2 terungkap persaingan antara Salomo dan Adonia dalam memperebutkan takhta yang dipenuhi intrik dan politik penyingkiran. Melalui analisis terhadap teks tersebut terlihat bahwa kisah tersebut tidak bisa dijadikan pembenaran teologis tetapi berperan sebagai pembelajaran agar hal yang sama tidak terulang kembali. Sebaliknya umat Kristiani juga perlu memahami bahwa politik adalah media perjuangan kasih dan keadilan kepada sesama.
\end{abstract}

Kata kunci: politik Kristiani; Salomo; Adonia; tafsir naratif; 1 Raja-raja 


\section{PENDAHULUAN}

Sebuah serial epik berjudul Game of Thrones yang tayang di salah satu siaran televisi berbayar di Indonesia memiliki rating yang sangat tinggi di $\mathrm{IMDb}$ (memperoleh nilai 9,5 dari 10). IMDb adalah singkatan dari Internet Movie Database, yang di dalamnya memuat berbagai macam judul film serta review dan pemberian rating dari para pakar di dunia perfilman dunia. Serial Game of Thrones sendiri diangkat dari novel fiksi popular karangan George G. Martin. Secara ringkas, serial tersebut berkisah tentang perebutan takhta di sebuah negeri khayalan bernama Westeros. Intrik politik sangat kental mewarnai jalannya cerita. Pembunuhan, penipuan, serta berbagai macam cara dilakukan demi menduduki takhta besi (Iron Throne), termasuk dengan mengorbankan saudara dan sahabat sendiri demi kepentingan politis.

Kebetulan dalam konteks Indonesia, tahun 2019 disebut-sebut sebagai tahun politik karena pada tahun ini, rakyat merayakan pesta demokrasi. Kontestasi dari para elit politik baik dalam konteks pemilihan legislatif maupun pemilihan presiden bak "genderang perang" yang mulai ditabuhkan oleh masing-masing

\footnotetext{
${ }^{1}$ Syailendra Persada, "Sebab Cekcok Beda Capres Berujung Maut: Rakyat Hanya Alat Politik - Fokus Tempo.Co," accessed February 3, 2019,
}

pihak yang berkepentingan di dalamnya. Politik mendadak menjadi salah satu "komoditi" andalan nan laris yang tak hanya diperbincangkan oleh para akademisi dan politisi tetapi juga menyentuh akar rumput. Menjelang pemilihan umum, seperti halnya pada tahun 2014 silam dan tahun-tahun sebelumnya, politik memang menjadi tagline popular di tengah masyarakat.

Sayangnya, politik praktis yang berlangsung kerap kali diwarnai sejumlah intrik yang menghalalkan segala macam cara demi mencapai tujuan termasuk dengan menyampaikan kabar bohong (hoaks) yang berpotensi memecah belah persatuan dan kesatuan. Bahkan karena persoalan politik, beberapa media melaporkan terjadinya sikap anarkis dari faksi serta pendukung pasangan calon yang berseberangan dan bahkan sampai berujung kepada kasus persekusi dan pembunuhan. ${ }^{1}$ Hal ini seolah memperteguh keyakinan bahwa politik adalah sesuatu yang kotor, tidak ada "orang yang suci" dalam berpolitik. Bagi sebagian orang, politik dianggap sudah terlalu identik dengan permainan, saling sikut, tipu muslihat, dan pencarian keuntungan bagi diri sendiri.

https://fokus.tempo.co/read/1149698/sebab-cekcokbeda-capres-berujung-maut-rakyat-hanya-alatpolitik. 
Pertanyaannya, benarkah politik adalah sesuatu yang kotor? Bagaimana sikap orang Kristen dalam menghadapi persoalan di bidang politik dalam hidup keseharian khususnya dalam konteks kontestasi dalam pemilihan umum? Untuk menjawab pertanyaan tersebut, dalam tulisan ini penulis akan menelusuri pandangan orang Kristen tentang politik serta memberikan pemahaman teologis biblis dimana orang percaya dapat belajar dari kisah yang sarat dengan nuansa politis sebagaimana yang terdapat dalam kitab 1 Raja-raja 1-2.

\section{METODE PENELITIAN}

Metode yang digunakan dalam artikel ini adalah metode tafsir naratif terhadap teks 1 Raja-raja 1 - 2. Penulisan dalam artikel ini menggunakan pendekatan diskriptif analitis, yaitu akan mendeskripsikan berbagai dinamika politik uamt Kristiani di Indonesia dan menganalisanya melalui penafsiran teks 1 Raja-raja 1-2 maupun berbagai pandangan teologis.

Tahapan yang dilakukan adalah dengan terlebih dahulu memaparkan hubungan antara orang Kristen di Indonesia dengan dunia politik. Selanjutnya dari pendiskripsian situasi tersebut dilakukan

\footnotetext{
${ }^{2}$ Alter I. Wowor, "Bolehkah Pendeta Berpolitik? Suatu Tinjauan Etika Kristen Terhadap Keterlibatan
}

analisis melalui penafsiran secara naratif terhadap teks 1 Raja-raja 1 - 2 dalam rangka melihat pergolakan politik di lingkungan kerajaan Israel. Hasil penafsiran tersebut kemudian direfleksikan ke dalam suatu pandangan teologis melalui upaya mendiskusikan hasil tafsiran tersebut dengan berbagai pandangan teologis dari para teolog di Indonesia.

\section{HASIL DAN PEMBAHASAN}

\section{Orang Kristen dan Politik}

Alter Imanuel Wowor mengungkapkan bahwa realitas korupsi yang masif, perseteruan elit politik yang berimbas pada ketidakstabilan pemerintahan, janji palsu yang disampaikan para politisi saat berkampanye demi menarik hati masyarakat, gratifikasi dan praktik suap-menyuap, praktik kolusi dan nepotisme pemerintahan, serta berbagai aksi demonstrasi organisasi mahasiswapemuda dan organisasi masyarakat demi memperjuangkan kepentingan politik sejumlah pihak, seakan telah menjadi tontonan yang lazim bagi masyarakat Indonesia sampai saat ini. Realitas ini yang mengakibatkan sebagian besar masyarakat Indonesia memiliki paradigma bahwa politik di Indonesia adalah sesuatu yang negatif dan kotor. $^{2}$ Padahal menurut 
Zakharia Ngelow, sejak era Orde baru, orang Kristen telah terlibat dalam dunia politik dengan kehadiran Partai Kristen Indonesia (Parkindo), satu-satunya partai politik Kristen sejak 1945, yang menyebut diri sebagai partai nasionalis yang berjuang untuk kepentingan bangsa dengan jalan menegakkan keadilan dan kedamaian di tanah Indonesia. ${ }^{3}$

Bahkan jika merunut jauh ke belakang, menurut Richard Daulay, sejak awal abad ke-19, sejak masuknya misionaris ke Indonesia, wawasan politik sudah dibawa oleh mereka tetapi masih bersifat sangat negatif. Hal ini terjadi karena badan zending yang datang yakni NZG di Belanda dan RMG di Jerman banyak dipengaruhi oleh wawasan politik pietisme yang menganggap politik itu kotor, duniawi, dan tidak sesuai dengan Injil. ${ }^{4}$ Secara umum ada 2 alasan para zending enggan membina orang Kristen dalam bidang politik. Pertama, alasan teologis yang menyatakan bahwa para pekabar Injil yang berlatar belakang pietisme itu tidak tertarik dan tidak merasa

\footnotetext{
${ }^{3}$ Zakaria J. Ngelow and Zakaria J. Ngelow, "Turut Membina Indonesia Sebagai Rumah Bersama Peran Gereja Dalam Politik Di Indonesia," Jurnal Jaffray 12, no. 2 (October 2, 2014): 213, accessed October 7, 2019,

http://ojs.sttjaffray.ac.id/index.php/JJV71/article/vi ew/16.

${ }^{4}$ Richard M. Daulay, Agama Dan Politik Di Indonesia: Umat Kristen Di Tengah Kebangkitan Islam (Jakarta: BPK Gunung Mulia, 2015), 90.
}

bertanggung jawab untuk masalah-masalah politik di lapangan pekabaran Injil. Kedua, alasan politik praktis yaitu sesuai peraturan pemerintahan jajahan Belanda, setiap pekabar Injil harus terikat pada prinsip rust en orde (ketentraman dan ketertiban). ${ }^{5}$

Menurut beberapa teolog, kekeliruan dalam memahami politiklah yang membuat banyak orang Kristen menganggap politik sebagai sesuatu yang kotor. Menurut Yewangoe, politik dapat dibedakan dalam dua pengertian atau matra yang tidak boleh dipisahkan satu sama lainnya. Matra pertama adalah tanggung jawab sebagai warga negara yang hidup dalam suatu masyarakat atau negara (polis). ${ }^{6}$ Polis adalah istilah Yunani yang mengacu pada tempat di mana kehidupan bersama dapat dibina dan dipupuk, tetapi berarti pula suasana di mana setiap orang yang berkehendak baik dapat saling membina dan membangun dirinya masingmasing bagi kesejahteraan polis itu sendiri. ${ }^{7}$ Secara sederhana, dalam pengertian ini, politik adalah kemauan bersama untuk membangun dan memelihara polis. ${ }^{8}$ Matra

\footnotetext{
${ }^{5}$ Ibid, 92 .

${ }^{6}$ Andreas A. Yewangoe and Weinata Sairin, SuaraSuara Menyeruak Udara: Serpihan-Serpihan Pemikiran Di Pusaran Kehidupan Kekinian (Jakarta: Pustaka Sinar Harapan, 2009), 95. ${ }^{7}$ Andreas A. Yewangoe, Agama Dan Kerukunan (Jakarta: BPK Gunung Mulia, 2001), 162.

${ }^{8}$ Ibid.
} 
atau pengertian ini didasari pada Yeremia 29:7, "Usahakanlah kesejahteraan kota ke mana kamu Aku buang, dan berdoalah untuk kota itu kepada Tuhan, sebab kesejahteraannya adalah kesejahteraanmu." Lewat persepektif tersebut, politik tidak dilihat sebagai suatu kenyataan demonis, tetapi dipandang sebagai kenyataan manusiawi. Dalam konsep ini, kehadiran pemerintah merupakan salah satu unsur yang dibutuhkan untuk meniadakan hal-hal yang bersifat demonis, dan hukum sebagai unsur yang lain juga dibutuhkan untuk mengatur kehidupan masyarakat. ${ }^{9}$

Politik dalam arti atau matra yang kedua adalah adalah upaya-upaya untuk memperoleh kekuasaan (power, macht). Ada perjuangan memperoleh kekuasaan (machtstrijd). Kekuasaan bukanlah sesuatu yang buruk, asal saja dipergunakan untuk kemaslahatan bersama. $^{10}$ Kekuasaan bukanlah tujuan pada dirinya, melainkan sarana untuk menghasilkan kebaikan bagi sebanyak mungkin orang. Matra yang kedua ini didasarkan pada ajakan rasul Paulus kepada umat di kota Roma untuk taat kepada pemerintah sebagai suatu sikap

\footnotetext{
${ }^{9}$ Ibid, 164.

${ }^{10}$ Yewangoe and Sairin, Suara-Suara Menyeruak Udara: Serpihan-Serpihan Pemikiran Di Pusaran Kehidupan Kekinian, 96.

${ }^{11}$ Andreas A. Yewangoe, Visi Kristen Mengenai Politik, Dalam Teologi Politik: Panggilan Gereja Di Bidang Politik Pasca Orde Baru, ed. Zakaria J. Ngelow (Makassar: Yayasan Oase INTIM, 2013), 91.
}

politik. Matra ini hendak menjelaskan bahwa kekuasaan yang terwujud dalam bentuk pemerintah bukanlah sesuatu yang jahat. Bagi Paulus, tidak ada pemerintah yang tidak berasal dari Allah dan ditetapkan oleh Allah (Rm. 13); bisa juga dibandingkan dengan perintah Yesus dalam Matius 22:15-22. Pemerintah dianggap sebagai pengemban amanat untuk mengurus polis (negara-kota). ${ }^{11}$

Menurut Abraham Silo Wilar, teologi, politik, dan keseharian orang Israel mewarnai kitab Kejadian hingga Raja-raja. Di sini Tuhan senantiasa terlibat dalam kehidupan Israel termasuk dalam kekuasaan duniawi. Oleh karena itu, memisahkan teologi dan politik malahan membuat politik dikuasai oleh orang-orang yang tidak konstruktif (akibatnya anggapan politik itu adalah hal yang kotor justru makin kental). ${ }^{12}$ Dalam konteks menghadapi tahun politik, bagaimana pemahaman politik yang seharusnya dimiliki orang percaya menurut Alkitab? Untuk dapat menarik pelajaran serta refleksi teologis yang mendalam tentang politik dalam Alkitab, pada bagian

\footnotetext{
${ }^{12}$ A. Silo Wilar, "Kristianitas \&amp; Politik Global Suatu Tinjauan Atas Konstruksi Teologi-Politik Tokoh-Tokoh Kristen Di Jerman Dan Lebanon," n.d., accessed April 8, 2019, https://www.academia.edu/32916461/Kristianitas_a nd_Politik_Global_Suatu_Tinjauan_atas_Konstruk si_Teologi-Politik_Tokohtokoh_Kristen_di_Jerman_dan_Lebanon.
} 
selanjutnya dari tulisan ini, penulis akan menelusuri kisah Salomo dan Adonia sebagai salah satu contoh kontestasi politis yang pernah tercatat dalam Kitab Suci sebagaimana terdapat dalam kitab 1 Rajaraja $1-2$.

\section{Adonia dan Salomo dalam Persaingan Menuju Takhta}

Secara politis, Daud adalah gambaran dari seorang raja Israel yang sukses. Nama Daud tak lekang dalam memori kolektif bangsa Israel. Ia adalah raja Israel yang termasyur dan dalam masa pemerintahannya, Israel mencapai puncak kejayaannya. Sayangnya, walau sukses dalam karir politik, Daud gagal dalam kehidupan rumah tangga. Anak pertama Daud, Amnon, memperkosa Tamar, adik Absalom (anak Daud Daud dari istri yang lain). Daud murka karena hal itu tetapi ia sama sekali tidak mengambil tindakan apaapa. Absalom yang murka kemudian membunuh Amnon lalu melarikan diri dan sekembalinya dari pelarian, ia menyusun rencana untuk membunuh Daud. Selanjutnya, para pembaca kitab Samuel akan menemukan bagaimana Absalom terpukul kalah dan mati dalam usahanya menggulingkan takhta Daud. Absalom tewas di tangan Yoab, panglima tentara

\footnotetext{
${ }^{13}$ St. Darmawijaya, Seluk Beluk Kitab Suci (Yogyakarta: Kanisius, 2009), 150.
}

Daud. Praktis, setelah kematian Absalom, Adonia mendaku diri sebagai anak pertama Daud yang memiliki klaim atas takhta segera setelah sang ayah meninggal.

Daud dalam 1 Raja-raja 1 digambarkan telah tua dan hanya bisa berbaring di tempat tidur. Hari-hari tua Daud sendiri diperkirakan menunjuk pada tahun 970 SM. Masa tua Daud dilayani oleh Abisag, seorang gadis Sunem dan masa tersebut ditandai dengan perebutan takhta di antara anak-anaknya. ${ }^{13}$ Adonia sebagai anak tertua menduga bahwa dirinyalah yang akan diangkat sebagai raja selanjutnya. Sayangnya, Daud sendiri tak pernah menyebut nama Adonia sebagai suksesornya. Akan tetapi karena begitu yakin bahwa dirinya akan ditunjuk menjadi raja, Adonia memilih untuk menetapkan dirinya sendiri dan dalam hal ini ia didukung oleh Yoab dan Abyatar.

Keyakinan Adonia ini bukanlah tanpa alasan sebab statusnya kini adalah sebagai anak tertua pasca kematian Absalom. Bahkan kitab raja-raja sendiri menyebut sosok Adonia sebagai pribadi yang elok perawakannya, mirip dengan Absalom (2Sam. 14:25). ${ }^{14}$ Lagi-lagi Daud menunjukkan sisi lemahnya sebagai seorang ayah dan kepala keluarga. Sama

\footnotetext{
${ }^{14}$ Lissa M. Wray Beal, 1 and 2 Kings: Apollos Old Testament Commentary (Downers Grove: InterVarsity Press, 2014), 70.
} 
seperti ketika ia tidak mengambil keputusan apa-apa ketika Amnon memperkosa Tamar -yang berujung pada pembunuhan yang dilakukan Absalom atas diri Amnon demikian pula sekarang Daud tak menyadari ada 2 faksi berseberangan di dalam istananya. ${ }^{15} \mathrm{Jika}$ di satu sisi ada faksi Adonia yang disokong oleh Yoab dan Abyatar, maka di sisi yang lainnya ada faksi Salomo yang mendapat dukungan dari Imam Zadok, Benaya, nabi Natan, serta para ksatria Daud. Zadok sendiri adalah imam saingan Abyatar, Benaya adalah kepala pasukan yang tak pernah akur dengan Yoab, sementara Natan berperan besar saat Salomo lahir. Natan juga yang paling tahu bagaimana hubungan Daud dengan Batsyeba, ibu Salomo, termasuk dalam kasus perselingkuhan mereka dahulu.

Brueggemann menyebut bahwa kedua faksi tersebut mewakili kondisi yang berbeda. Faksi Adonia kemungkinan besar mewakili konservatisme suku lama sedangkan faksi Salomon yang dipimpin oleh Natan merupakan koalisi ambisius dari mereka yang bersemangat untuk pembangunan sosial dan kemajuan publik. Namun yang jelas, keduanya sama-sama berjuang untuk mengendalikan masa depan di tangan mereka. Kedua faksi tersebut juga berupaya mewujudkan komitmen ideologis yang melibatkan lebih dari sekadar ambisi pribadi. $^{16}$

Tak heran saat mengetahui Adonia mengangkat diri menjadi raja, Natan buruburu menemui Batsyeba. Natan meyakini bahwa hal itu akan mengancam keselamatan Batsyeba dan Salomo sehingga ia meminta dirinya bekerjasama agar Daud segera menyerahkan takhta kepada Salomo sehingga mereka semua selamat dari potensi ancaman dari Adonia. Peran seorang perempuan juga ditonjolkan dalam narasi ini. Batsyeba memainkan peran yang sangat krusial sebagai penentu dalam perebutan takhta ini. Batsyeba adalah istri termuda Daud dan narasi 1 Raja-raja mengisahkan bahwa menjelang hari kematian Daud, Batsyeba adalah sosok yang paling sering bersama Daud dibanding para istrinya yang lain. Kedekatan itulah yang kemudian digunakan oleh nabi Natan untuk mengambil hati Daud agar segera memenuhi janji untuk menjadikan Salomo sebagai raja Israel. Natan mengatur skenario sedemikian rupa dan memberitahu Batsyeba mengenai apa yang harus dikatakannya.

\footnotetext{
${ }^{16}$ Walter Brueggemann, 1 and 2 Kings: $A$ Commentary (Georgia: Smyth \& Helwys Publishing, 2000), 21.
} 
Batsyeba dengan cerdik mengingatkan Daud akan sumpahnya demi TUHAN bahwa Salomo akan menjadi raja. Ia menceritakan bahwa kenyataannya sekarang Adonia telah menjadi raja. Dengan cerdik Batsyeba menyebut bahwa semua anak raja mendukungnya kecuali Salomo, hamba Daud. Natan yang telah mengatur segala sesuatunya lalu datang dan membenarkan pernyataan sang permaisuri. Ia bahkan seolah ikut "memanas-manasi" suasana dengan mengatakan bahwa dirinya, Imam Zadok, Benaya, dan Salomo sama sekali tak mendapatkan undangan tersebut. ${ }^{17}$ Daud yang berada di bawah bujukan Batsyeba kemudian mengucapkan janjinya, "Demi TUHAN yang hidup, yang telah membebaskan nyawaku dari segala kesesakan, pada hari ini aku akan melaksanakan apa yang kujanjikan kepadamu demi TUHAN, Allah Israel, dengan sumpahini: Anakmu Salomo akan menjadi raja sesudah aku, dan dialah yang akan duduk di atas takhtaku menggantikan aku” (1Raj. 1:29-30). Segera setelah Batsyeba sukses membuat Daud mengucapkan janjinya mengangkat Salomo, Imam Zadok langsung mengurapi Salomo berdasarkan penetapan sang raja. Setelah diurapi, Salomo diarak ke istana dengan bagal tunggangan Daud sendiri.

\footnotetext{
${ }^{17}$ Beal, 1 and 2 Kings: Apollos Old Testament Commentary, 72.
}

Bruegemann

kemudian menggambarkan bahwa pada titik ini muncullah adegan kecemasan mendalam di antara partai koalisi Adonia ketika kudeta Salomo tersebut sampai di telinga mereka. Para tamu undangan perayaan kemenangan Adonia mendadak gemetar dan lari ketakutan (1Raj. 1:49). Sementara Adonia memilih melarikan diri ke tempat kudus yang aman (1:50). ${ }^{18}$ Koalisi Adonia yang sebelumnya larut dalam perayaan kemenangan politis kini diliputi ketakutan yang tak terkatakan sebab kini nyawa mereka yang berbalik berada dalam bahaya. Adonia sadar posisinya sekarang sangat lemah sebab ia mengangkat diri tanpa persetujuan raja. Ia pun dapat dianggap sebagai orang yang berusaha merebut takhta. Itu sebabnya ia lari mencari selamat dan setelah Salomo berjanji tidak akan membunuhnya, ia pun segera menghadap raja dan mau tidak mau ia harus mengakui bahwa Salomo, adiknya adalah raja yang sah demi keselamatan nyawanya sendiri.

Tindakan Salomo Dalam Mengokohkan Takhtanya

Setelah resmi menjadi raja, Salomo tak tinggal diam dan langsung mengambil langkah strategis guna mengamankan takhtanya dari potensi ancaman yang akan

\footnotetext{
${ }^{18}$ Brueggemann, 1 and 2 Kings: A Commentary, 22.
} 
datang. Salomo segera mengambil langkah guna menyingkirkan lawan politiknya. Kalau sebelumnya Salomo membiarkan Adonia hidup, maka kini Salomo memiliki celah untuk menyingkirkan sang kakak untuk selama-lamanya. Momen itu hadir ketika Adonia yang kurang cerdas mengajukan permintaan bodoh yakni meminta Abisag, gadis Sunem yang merawat Daud semasa hidup. Permohonan ini diampaikan lewat Batsyeba yang memang punya peran penting dan dianggap bisa mengajukan permintaan kepada raja. Permintaan ini juga disertai dengan sebuah pengingat bahwa dirinyalah yang sebenarnya pantas menjadi raja dan permintaan akan diri Abisag dianggap sebagai hadiah pertukaran yang layak untuk itu. Menurut Brueggemann, permintaan untuk perawan muda mengingatkan pembaca akan politik seksual khas Daud. Permintaan dan pemberian seorang perempuan (selir) sebenarnya adalah sebuah usaha mengirimkan sinyal kepada publik tentang politik kejantanan (politic of virility) bahkan legitimasi hak atas takhta kerajaan (bandingkan kisah Absalom yang memberontak, menguasai takhta dan tidur dengan gundik serta selir ayahnya). ${ }^{19}$

Tindakan ini dianggap sebagai usaha merongrong takhta sehingga Salomo memerintahkan Benaya untuk memancung Adonia (1Raj. 1:13-25). Setelah Adonia mati, kini Salomo langsung mengincar sosok-sosok di belakang Adonia yang secara jelas menyatakan dukungan kepada Adonia untuk menjadi raja yakni Abyatar dan Yoab. Namun mengingat jasa besar dari Imam Abyatar yang setia bersama-sama dalam perjuangan dengan Daud, ia tidak dibunuh namun dipecat dari jabatannya sebagai Imam dan diusir kembali ke Anatot, kampung halamannya. Hal ini sesuai dengan janji Daud kepada Abyatar sebelumnya: "Tinggallah padaku, janganlah takut; sebab siapa yang ingin mencabut nyawamu, ia juga ingin mencabut nyawaku; di dekatku engkau aman" (1 Sam. 22:23). ${ }^{20}$ Sementara itu nasib Yoab berakhir dengan tragis. Panglima perang Daud tersebut tewas di dalam kemah TUHAN setelah Yoyada memancung dirinya. Hal ini memang ironis sebab jika dirunut ke belakang, Yoab seperti halnya Abyatar, telah banyak berjasa untuk Daud dan kerajaan Israel. Bahkan Yoab sendiri yang sukses membasmi pemberontakan Absalom dan membunuh anak Daud tersebut dengan tombaknya sendiri. Sekali lagi, dalam politik seolah tak ada kawan sejati dan abadi karena yang abadi adalah kepentingan itu sendiri.

\footnotetext{
${ }^{19}$ Ibid, 31.
}

${ }^{20}$ Ibid, 34. 
Sesudah itu, Salomo memberikan jabatan kepada koalisi pendukungnya dengan mengangkat Zadok sebagai imam menggantikan Abyatar sedangkan Benaya diangkat menjadi panglima perang menggantikan kedudukan Yoab. Tampak jelas bahwa dalam sistem kerajaan tersebut, seorang Imam merupakan jabatan politis yang memainkan peran sangat strategis di Istana, bukan sekadar pelayan Tuhan. Imam pun terlibat dalam politik praktis! Bahkan menurut Brueggemann, tindakan pengurapan Salomo menjadi raja oleh Imam Zadok sangat sarat dengan nuansa politis. Pengurapan tersebut adalah tindakan subversif dan revolusioner yang membangkitkan aktivitas politik. ${ }^{21}$ Hal lain yang tak kalah menarik adalah ada sesuatu yang ironis tentang nama Salomo (Solomon = shalom "damai"), sementara caranya merebut takhta dan mengokohkan pemerintahannya justru berakar pada kekerasan yang jarang dikaitkan dengan shalom. $^{22}$ Tak berhenti sampai di situ, Salomo kembali mengambil langkah strategis demi menjamin keamanan negeri. Ia menjalin hubungan baik dengan Mesir serta menikahi putri Firaun dalam pernikahan politis sehingga dengan cara ini, ia menyingkirkan kemungkinan ancaman dari daerah Selatan. Suatu sikap yang di

\footnotetext{
${ }^{21}$ Ibid, 23.
}

kemudian hari menjadi salah satu sebab kehancuran kerajaan Israel.

Membangun Pemahaman Politik yang Alkitabiah: Sebuah Refleksi Teologis

Melalui kisah di atas, pelajaran apa yang dapat dipetik sebagai ancangan dasar orang Kristen berpolitik praktis melalui kasus Salomo dan Adonia tersebut? Kisah Adonia dan Salomo menjadi bukti bagaimana intrik politik adalah sesuatu yang sudah lazim dilakukan pada masa lampau. Demikian pula pada masa kini, negara-negara dengan sistem demokrasi juga terlibat di dalamnya. Lalu bagaimana respons orang Kristen tatkala berhadapan dengan persoalan demikian? Disukai atau tidak, orang Kristen dan gereja hidup dalam dinamika politik, demikian halnya dengan orang Kristen di Indonesia. Beberapa pelajaran penting bisa diambil dari kisah Adonia dan Salomo dalam memperebutkan takhta Daud. Pertama, kisah ini sekali lagi menunjukkan sisi lemah kepemimpinan seorang Daud. Bisa dikatakan bahwa sang raja Israel yang termasyhur tidak mempersiapkan kader yang benar-benar tepat jikalau kelak dirinya mangkat. Daud memang sukses dalam karir politik sebagai raja, tapi ia sekaligus gagal menjadi kepala rumah tangga yang sukses. Kedua, kisah ini juga memperlihatkan betapa kehidupan

${ }^{22}$ Ibid. 
sebuah keluarga juga bisa hancur karena politik praktis.

Kisah ini seolah kembali mempertegas pemahaman orang Kristen bahwa politik itu memang kotor. Akan tetapi sebenarnya dari kisah ini, orang percaya bisa menarik banyak pelajaran dalam memahami politik dan bagaimana berpolitik secara benar dan etis. Orang Kristen juga harus membedakan antara politik praktis dan politik yang mengedepankan etika yang benar sebab politik pada hakikatnya bukanlah sesuatu yang kotor. Kisah Salomo dan Adonia tentu tak bisa dijadikan blue print dalam peran politik gereja dan orang Kristen di tengah masyarakat. Justru praktik politik yang menghalalkan segala cara untuk dapat memperoleh kekuasaan dengan menempuh segala macam cara termasuk politik penyingkiran adalah sesuatu yang tak dapat dibenarkan. Sebagaimana diungkapkan oleh Abraham Silo Wilar dalam bagian awal tulisan ini, teologi dan politik adalah 2 hal yang tidak dapat dipisahkan. Akan tetapi, kegiatan berteologi tak bisa dilakukan secara sembarangan. Perlu dilakukan pembingkaian dalam usaha berteologi yang melibatkan politik agar terjadi interaksi yang konstruktif di antara

\footnotetext{
${ }^{23}$ Wilar, "Kristianitas \&amp; Politik Global Suatu Tinjauan Atas Konstruksi Teologi-Politik TokohTokoh Kristen Di Jerman Dan Lebanon," 14.
}

keduanya. Sebuah teologi politik yang membangun dan memberdayakan ${ }^{23}$ Bukan teologi yang menebar ketakutan dan teror seperti yang ditunjukan oleh dalam kisah Adonia dan Salomo. Selain itu, menarik pula untuk mencermati pendapat Zakharia Ngelow berikut ini:

Dalam pelayanan politik gereja, bukan terutama supaya orang-orang Kristen berkuasa di berbagai posisi penting untuk memuluskan kepentingan orang Kristen atau kepentingan gereja, melainkan supaya orang-orang yang baik, profesional dan berintegritas, dari berbagai latar belakang agama, Kristen atau bukan Kristen, bersamasama melayani kepentingan seluruh masyarakat tanpa membeda-bedakan. Politik Kristen bukan politik kekuasaan dan kepentingan, melainkan politik pelayanan dan keadilan bagi seluruh warga masyarakat bangsa kita. ${ }^{24}$

Hal tersebut dipertegas oleh Eddy Kristiyanto yang mengatakan bahwa orang Kristen perlu untuk bersikap politis seperti halnya Yesus sendiri yang bersikap politis.

Dalam keterlibatan-Nya dengan dunia dalam sejarah manusia, Allah yang menjelma dalam diri Yesus tidak bersikap netral, melainkan melakukan suatu affirmative action yang nyata, dengan memihak manusia yang lemah dan berdosa, agar mereka diselamatkan melalui penebusan. Pilihan tersebut menyangkut

\footnotetext{
${ }^{24}$ Ngelow and Ngelow, "Turut Membina Indonesia Sebagai Rumah Bersama - Peran Gereja Dalam Politik Di Indonesia,” 224.
} 
nasib orang banyak yang hendak dibela, sehingga dengan jelas dapat dinyatakan bahwa Allah itu politis. ${ }^{25}$

Paulinus Yan Olla menyatakan bahwa politik adalah jalan kesucian. Kesadaran akan politik sebagai jalan kesucian didasari pada keyakinan bahwa semua anggota gereja (pengikut Kristus) dipanggil dan diundang mengikut Yesus untuk mewujudkan keselamatan. Keselamatan yang dilakukan Yesus bukan hanya terjadi pada kehidupan kelak setelah kematian atau menyangkut eskatologi, tetapi juga meliputi apa yang sudah diwujudkan di dalam dunia ini. ${ }^{26}$ Keterlibatan umat beriman dalam setiap pekerjaan dan aspek dalam dunia ini, termasuk politik, merupakan medan untuk mewujudkan iman akan keselamatan yang dikerjakan oleh Yesus. Keselamatan yang diwartakan Yesus adalah sebuah keselamatan yang integral. Keselamatan itu menyangkut seluruh dimensi kehidupan manusia dan menjangkau semua orang. Dengan demikian, iman tidak boleh direduksi pada ajaran abstrak (dogmatikadoktrinal) saja, melainkan juga perlu mendapat pengungkapan nyata untuk menyapa manusia dalam segala dimensi kehidupannya. Oleh karena manusia telah

${ }^{25}$ Eddy Kristiyanto, Sakramen Politik: Mempertanggungjawabkan Memoria (Yogyakarta: Lamalera, 2008), xi. dikasihi Allah, maka orang beriman terpanggil untuk menanggapi kasih itu. Orang beriman harus mewujudkan kasih Allah itu dalam segala aspek kehidupan, termasuk dalam dunia politik. ${ }^{27}$

Dalam rangka keterlibatan gereja atau orang Kristen dalam dunia politik praktis, gereja atau orang Kristen harus memiliki prinsip-prinsip yang perlu dipegang agar supaya tidak terlena dalam kepentingan pribadi atau golongan tertentu seperti yang diungkap oleh Yewangoe. Prinsip-prinsip yang dimaksud dapat diringkaskan sebagai berikut:

1) Kekuasaan yang dimiliki adalah kekuasaan yang melayani, bukan kekuasaan demi kekuasaan; 2) Yang diperjuangkan adalah kesejahteraan bersama, bukan sekedar kesejahteraan sendiri yang pada akhirnya hanya akan menimbulkan salah paham di dalam masyarakat.; 3) Dalam penyelenggaraan kekuasaan, mestinya etika dan moral kekuasaan dikedepankan. Perlu ada keseimbangan antara kekuasaan (power), keadilan (justice), dan kasih (love). 4) Dengarkanlah selalu suara hati yang benar. Kompromi politik mungkin tidak terhindarkan tapi ada batasnya. Apabila kompromikompromi itu telah menyentuh hal yang paling prinsip dalam iman Kristen, maka "adalah lebih baik taat kepada Allah ketimbang kepada manusia" (Kis. 5:29); 5) Gereja tidak boleh berhenti menjalankan fungsi atau pelayanan pastoralnya terhadap

\footnotetext{
${ }^{26}$ Paulinus Yan Olla, Spiritualitas Politik:

Kesucian Politik Dalam Perspektif Kristiani

(Jakarta: PT Gramedia Pustaka Utama, 2014), 68.

${ }^{27}$ Ibid, 68-69.
} 
anggota atau umatnya yang berkecimpung dalam dunia politik (praktis). 6) Lebih daripada itu, gereja tidak boleh mengidentikkan diri dengan atau sebagai partai politik. Gereja adalah suatu institusi yang mengatasi semua partai politik. Dalam "pengambilan jarak" yang demikian, maka gereja memiliki kekuatan moril. ${ }^{28}$

Jelaslah bahwa pelayanan politik adalah sesuatu yang dapat dikerjakan oleh gereja (orang Kristen). Tetapi perlu diingat bahwa pelayanan politik tersebut bukan untuk memperjuangkan "kepentingan Kristen" semata melainkan sebuah pelayanan yang memperjuangkan kepentingan masyarakat secara keseluruhan. Sebagaimana diungkap oleh P. J. Hoedemaker yang dikutip oleh Zakharia Ngelow yang menolak isolasi Kristen dalam lingkaran sosial tersendiri sekaligus mendorong kehadiran kesaksian Kristen dalam semua bidang dan institusi sosial. ${ }^{29}$ Gereja harus terjun dan melayani dalam bidang politik tetapi tak boleh ikut terlibat dalam politik praktis (politik praktis). Sebagaimana dikatakan oleh Ngelow bahwa gereja bukan organisasi politik yang mengarahkan warganya untuk menjatuhkan pilihan politik kepada oknum

\footnotetext{
${ }^{28}$ Andreas A. Yewangoe, Tidak Ada Penumpang Gelap: Warga Gereja, Warga Bangsa (Jakarta: Biro Penelitian dan Komunikasi PGI \& BPK Gunung Mulia, 2009) 224-225.

${ }^{29}$ Zakaria J. Ngelow, "Beberapa Catatan Mengenai Politik Kristen Di Indonesia," in Teologi Politik:
}

tertentu. Hal ini sekali lagi adalah bentuk penyelewengan dan kekeliruan yang dilakukan oleh gereja walaupun dengan alasan untuk berlindung kepada penguasa. Bila gereja terlibat politik praktis, akibatnya bisa sangat buruk. Bahkan tak jarang terjadi ada warga gereja yang sampai menjual suaranya kepada tokoh politik tertentu untuk pembangunan gedung gereja. Hal ini termasuk money politics dan secara teologis hal tersebut adalah dosa. ${ }^{30}$ Menghalalkan segala cara termasuk dalam konteks kisah Adonia vs Salomo tak bisa jadi pembenaran bagi orang Kristen yang terjun di dunia politik saat ini. Kisah salomo dan Adonia adalah tragedi di masa lampau yang harus dihindari. Kisah tersebut seolah juga menunjukkan bagaimana sosok pemimpin kegamaan (nabi istana) tak lepas dari lumuran darah (tentu saja konteks kisah ini berbeda dengan kontestasi politik yang terjadi di dunia modern), akan tetapi tetap saja ada pelajaran yang bisa dipetik. Saat seorang pemimpin keagamaan terjun dalam politik, maka konsekuensinya akan cukup berat sebab ia akan kesulitan menghadirkan pesan profetik bagi semua. Sukar baginya untuk bersikap netral dan tidak memihak.

Panggilan Gereja Di Bidang Politik Pascaorde Baru, ed. Zakaria J. Ngelow (Makassar: Yayasan OASE INTIM, 2013), 28.

${ }^{30}$ Ngelow and Ngelow, "Turut Membina Indonesia Sebagai Rumah Bersama - Peran Gereja Dalam Politik Di Indonesia,” 226. 


\section{KESIMPULAN}

Menyikapi tahun politik, orang Kristen diajak untuk kembali memahami politik secara benar, sehingga tak jatuh pada politik praktis yang menggunakan segala macam cara termasuk menyebarkan berita bohong, ujaran kebencian dan menyingkirkan lawan politik untuk mencapai tujuan. Kisah Adonia dan Salomo tentu saja tak bisa dijadikan pembenaran untuk melakukan politik penyingkiran demi merebut kekuasaan kisah kekerasan yang terjadi memang mewarnai kerajaan Israel yang berada dalam peralihan kekuasaan dari Daud. Akan tetapi kisah tersebut dapat menjadi pelajaran agar praktik kekerasan untuk kepentingan golongan tertentu tidak kembali terulang. Dalam konteks masa kini, politik gereja adalah bentuk pelayanan seperti halnya Yesus yang berkarya sekaligus berdaulat dalam segala aspek kehidupan manusia termasuk dalam bidang politik. Kemuliaan Allah lah yang harus dinyatakan dalam politik yaitu untuk mewujudkan kesejahtEraan bersama. Orang Kristen harus memahami bahwa politik adalah wadah yang disediakan oleh Allah. Oleh karena itu, kekuasaan yang dijalankan semestinya untuk kepentingan bersama yang dilandasi dengan keadilan dan kasih kepada sesama.

\section{DAFTAR PUSTAKA}

Beal, Lissa M. Wray. 1 and 2 Kings: Apollos Old Testament Commentary. Downers Grove: InterVarsity Press, 2014.

Brueggemann, Walter. 1 and 2 Kings: A Commentary. Georgia: Smyth \& Helwys Publishing, 2000.

Darmawijaya, St. Seluk Beluk Kitab Suci. Yogyakarta: Kanisius, 2009.

Daulay, Richard M. Agama Dan Politik Di Indonesia: Umat Kristen Di Tengah Kebangkitan Islam. Jakarta: BPK Gunung Mulia, 2015.

Kristiyanto, Eddy. Sakramen Politik: Mempertanggungjawabkan Memoria. Yogyakarta: Lamalera, 2008.

Marsunu, Y. M. Seto. "Salomo Dan Adonia: Pertarungan Untuk Merebut Takhta." Wacana Biblika 19, no. 1 (2019).

Ngelow, Zakaria J. "Beberapa Catatan Mengenai Politik Kristen Di Indonesia." In Teologi Politik: Panggilan Gereja Di Bidang Politik Pascaorde Baru, edited by Zakaria J. Ngelow. Makassar: Yayasan OASE INTIM, 2013.

Ngelow, Zakaria J., and Zakaria J. Ngelow. "Turut Membina Indonesia Sebagai Rumah Bersama - Peran Gereja Dalam Politik Di Indonesia." Jurnal Jaffray 12, no. 2 (October 2, 2014): 213. Accessed October 7, 2019. http://ojs.sttjaffray.ac.id/index.php/JJ V71/article/view/16.

Olla, Paulinus Yan. Spiritualitas Politik: Kesucian Politik Dalam Perspektif Kristiani. Jakarta: PT Gramedia Pustaka Utama, 2014.

Syailendra Persada. "Sebab Cekcok Beda Capres Berujung Maut: Rakyat Hanya Alat Politik - Fokus Tempo.Co." Accessed February 3, 2019. 
https://fokus.tempo.co/read/1149698/s ebab-cekcok-beda-capres-berujungmaut-rakyat-hanya-alat-politik.

Wilar, A. Silo. "Kristianitas \&amp; Politik Global Suatu Tinjauan Atas Konstruksi Teologi-Politik TokohTokoh Kristen Di Jerman Dan Lebanon," n.d. Accessed April 8, 2019.

https://www.academia.edu/32916461/ Kristianitas_and_Politik_Global_Suat u_Tinjauan_atas_Konstruksi_Teologi -Politik_Tokoh-

tokoh_Kristen_di_Jerman_dan_Leban on.

Wowor, Alter I. "Bolehkah Pendeta Berpolitik? Suatu Tinjauan Etika Kristen Terhadap Keterlibatan Pendeta GMIM Dalam Bidang Politik Praktis." Sekolah Tinggi Teologi Filsafat Jakarta, 2015.
Yewangoe, Andreas A. Agama Dan Kerukunan. Jakarta: BPK Gunung Mulia, 2001.

- Tidak Ada Penumpang Gelap: Warga Gereja, Warga Bangsa. Jakarta: Biro Penelitian dan Komunikasi PGI \& BPK Gunung Mulia, 2009.

Visi Kristen Mengenai Politik, Dalam Teologi Politik: Panggilan Gereja Di Bidang Politik Pasca Orde Baru. Edited by Zakaria J. Ngelow. Makassar: Yayasan Oase INTIM, 2013.

Yewangoe, Andreas A., and Weinata Sairin. Suara-Suara Menyeruak Udara: Serpihan-Serpihan Pemikiran Di Pusaran Kehidupan Kekinian. Jakarta: Pustaka Sinar Harapan, 2009. 